\title{
Elevated concentrate-to-forage ratio in dairy cow rations is associated with a shift in the diameter of milk fat globules and remodeling of their membranes
}

\author{
Nurit Argov-Argaman, ${ }^{* 1}$ Ronit Mesilati-Stahy, ${ }^{*}$ Yogev Magen, ${ }^{*}$ and Uzi Moallem† \\ *Department of Animal Science, The Robert H. Smith Faculty of Agriculture, Food and Environment, The Hebrew University of Jerusalem, \\ Rehovot 76100 , Israel \\ †Department of Ruminant Science, Institute of Animal Science, ARO, The Volcani Center, POB 6 Bet-Dagan, Israel
}

\begin{abstract}
We examined the effects of concentrate-to-forage ratio in dairy cow rations on milk-fat composition, with a specific focus on the structure of milk fat globules (MFG). Twenty-four Holstein cows, $153 \mathrm{~d}$ in milk, were assigned to 2 dietary treatments in a crossover design study. Treatments were (1) high-concentrate (65\%), low-forage (35\%; HCLF) diet and (2) low-concentrate (35\%), high-forage (65\%; LCHF) diet. The mean diameter of the MFG; plasma concentrations of insulin, glucose, and nonesterified fatty acids (FA); and the composition and concentrations of milk FA and polar lipids were determined. Concentrations of insulin were $56 \%$ higher, and those of nonesterified FA $46 \%$ lower, in the HCLF than in the LCHF diet. The milk yield was $8.5 \mathrm{~kg} / \mathrm{d}$ higher and yields of fat, protein, and lactose were 180,350 , and $403 \mathrm{~g} / \mathrm{d}$ higher, respectively, in the HCLF versus LCHF diet. Milk FA composition differed between treatments, with 1.5 and 1.0 percentage units higher saturated and polyunsaturated FA concentrations, respectively, in the HCLF versus LCHF diet. Mean MFG diameter tended to be smaller $(0.2 \mu \mathrm{m})$ in the HCLF diet than in the LCHF diet, associated with increased daily phospholipids yield (34\%), lower phosphatidylserine and higher phosphatidylcholine concentrations. In conclusion, the decreased milk and fat yields in the LCHF diet were associated with remodeling of the MFG membrane and with the secretion of larger MFG. Membrane remodeling of the mammary epithelium membranes seems to play a role in regulating MFG size.
\end{abstract}

Key words: high-forage diet, milk fat globule, phospholipid, membrane

Received March 27, 2014.

Accepted June 26, 2014.

${ }^{1}$ Corresponding author: argov.nurit@mail.huji.ac.il

\section{INTRODUCTION}

Milk fat consists of 95 to $98 \%$ triglycerides (TG) and only 1 to $2 \%$ phospholipids (PL), depending on animal, diet, and lactation stage (Jensen, 2002). Triglycerides and PL differ in their FA composition, with a higher concentration of SFA and a lower concentration of PUFA in the TG fraction than the PL fraction (Bitman and Wood, 1990). Due to their different FA compositions and molecular structures, when ingested as part of the human diet, TG and PL induce different metabolic and physiological responses, with health-promoting responses attributed to the PL. For example, dietary supplementation of 2.5 to $5 \%$ PL is associated with a variety of health-promoting bioactivities, such as improved plasma lipid profile, decreased postprandial cholesterol absorption, and even reduced rates of colon cancer pathogenesis (Dillehay et al., 1994; Burgess et al., 2005). Therefore, health and nutritional implications exist for understanding how the relative concentrations of PL in milk are determined.

Milk fat is secreted in a unique structure termed milk fat globule (MFG). The MFG consists of a TG core covered with 3 layers of PL, termed the MFG membrane (MFGM; Mather and Keenan, 1998). The size distribution of MFG in bovine milk ranges over 3 orders of magnitude, from less than $200 \mathrm{~nm}$ to over $15 \mu \mathrm{m}$ (Mulder and Walstra, 1974). The weight ratio between TG and PL is determined by the MFG size, with a lower ratio (Mesilati-Stahy and Argov-Argaman, 2014) and higher PL concentration (Lopez et al., 2008) in smaller globules. Therefore, the mechanisms controlling MFG size also determine the lipid profile of milk in terms of both bioactive lipid components such as PL and unsaturated FA, and hence can alter the milk dietary and health properties. The size of the MFG also influences the moisture content of dairy products (Michalski et al., 2004), dairy product rennet gel properties (Michalski et al., 2002), and cheese firmness (Michalski et al., 2003). Therefore, the importance of MFG size extends beyond its health implications to dairy-product quality. 
The mechanisms governing the size variations of MFG are not clear. Milk total fat content has been suggested as a predictor of MFG mean diameter (ElZeini, 2006), because the 2 factors are positively correlated, as also suggested by others (Couvreur et al., 2007; Lopez et al., 2008; Ménard et al., 2010). Also, dietary treatments that are expected to change milk fat content, such as n-3 FA supplementation and pasture compared with a corn silage-based diet (Avramis et al., 2003; Wiking et al., 2003; Couvreur et al., 2007), were also associated with altered MFG size. However, other studies have shown no significant correlation between fat content and MFG size (King, 1957; Walstra, 1969; Wiking et al., 2004).

Other parameters that have been shown to modulate milk fat content and MFG size are lactation stage (Mesilati-Stahy and Argov-Argaman, 2014) and genetic disposition (Couvreur et al., 2007; Argov-Argaman et al., 2013). Interestingly, conditions that induce changes in MFG mean diameter also change milk PL content and composition (Lopez et al., 2008; Argov-Argaman et al., 2012; Mesilati-Stahy et al., 2012), suggesting a link between the metabolic pathways regulating the composition of the mammary gland cell membranes and MFG size. The effect of altered composition of MFGM on MFG size is still unclear, although in other cell models, regulation of intracellular lipid droplet size through altered membrane composition has been demonstrated (reviewed by Thiam et al., 2013).

Our hypothesis was that modulation of milk fat yield and concentration in response to ration composition would be associated with altered MFG mean diameter, possibly due to changes in MFG PL composition. This would allow us to study the structural regulation of MFG. Modulation of milk fat yield and concentration was achieved by changing the forage-to-concentrate ratio in dairy cow rations.

\section{MATERIALS AND METHODS}

\section{Milk Sampling and Content Analysis}

The procedures used in this study were approved by the Volcani Center Animal Care Committee. The experiment was conducted at the Volcani Center experimental farm in Bet Dagan, Israel. Twenty-four Israeli-Holstein cows were housed in covered loose pens with adjacent outside yards and were divided into 2 treatment groups by milk yields, DIM, parity, and BW. These 2 groups of cows averaged (mean \pm SD), respectively, $46.1 \pm 4.8$ and $45.9 \pm 4.8 \mathrm{~kg}$ of milk/d, $155.5 \pm$ 28 and $151.4 \pm 27$ DIM, parities $3.1 \pm 1.4$ and $3.1 \pm$ 1.4 , and $665.3 \pm 35.1$ and $656.8 \pm 50.4 \mathrm{~kg}$ of BW.
The treatments were as follows: (1) high-concentrate, low-forage (HCLF) diet - cows were fed typical Israeli milking-cow rations consisting of $65 \%$ concentrate and $35 \%$ forage; and (2) low-concentrate, high-forage (LCHF) diet - cows were fed a ration consisting of 35\% concentrate and $65 \%$ forage. The composition of both diets is presented in Table 1 . The study was conducted in a crossover design, with a 4 -wk experimental period.

Cows were milked 3 times daily and milk yields were recorded electronically at each milking. Cows were also weighed automatically after each milking on a walking electronic scale (S.A.E. Afikim, Kibbutz Afikim, Israel). Milk samples were collected weekly from 3 consecutive milking sessions by the Afimilk sampling system (S.A.E. Afikim), which enables sampling throughout an entire milking session. A composite from each day for each cow was collected proportional to the milk yield at each individual milking. This protocol allowed us to overcome the variations in milk solids composition that can occur throughout the day. The representative sample was aliquoted and the first aliquot was mixed with bronopol (2-bromo-2-nitropropane-1,3-diol and 2-bromo-2-nitropropanol) for component analysis. Milk fat, protein, and lactose contents were determined by infrared analysis (IDF, 2000) at the laboratories of the Israeli Cattle Breeders' Association (Caesarea, Israel). Also, SCC was determined in fresh milk samples. A second aliquot was frozen at $-20^{\circ} \mathrm{C}$ for analysis of milk FA and PL composition by gas chromatography and HPLC.

Blood samples were taken twice per week (Monday and Wednesday) $2 \mathrm{~h}$ before feeding throughout the study from the coccygeal vein, using vacuum tubes containing lithium heparin (BD, Plymouth, UK). The tubes were immediately placed on ice and centrifuged at $3,000 \times g$ for $15 \mathrm{~min}$ at room temperature. Plasma was separated and frozen at $-32^{\circ} \mathrm{C}$ pending analysis.

\section{Chemical Analyses of Plasma Hormones and Metabolites}

Plasma insulin concentration was determined by RIA (Diagnostic Products Corp., Los Angeles, CA), with intra- and interassay coefficients of variation of 7.2 and $5.1 \%$, respectively. Plasma glucose concentration was determined with a glucose reagent kit (Glucose UV $10 \times 50 \mathrm{~mL}$; Raichem, San Diego, CA), with intra- and interassay coefficients of variation of 2.8 and $2.3 \%$, respectively. Plasma NEFA concentrations were determined with the Wako NEFA C test kit (Wako Chemicals GmbH, Neuss, Germany), with intra- and interassay coefficients of variation of 7.1 and $6.3 \%$, respectively. 
Table 1. Ingredients and chemical compositions (\% of DM, unless otherwise indicated) of the high-concentrate, low-forage (HCLF) and low-concentrate, high-forage (LCHF) diets

\begin{tabular}{lcc}
\hline & \multicolumn{2}{c}{ Diet } \\
\cline { 2 - 3 } Item & HCLF & LCHF \\
\hline Ingredient & \\
Corn grain, ground & 13.0 & 5.8 \\
Barley grain, rolled & 6.5 & - \\
Wheat grain & 6.5 & 5.1 \\
Rapeseed meal & 2.0 & - \\
Soybean meal & 1.8 & 11.9 \\
Sunflower meal & 4.5 & - \\
Corn gluten feed & 12.9 & 1.5 \\
Cottonseed & 2.0 & 1.0 \\
Corn silage & 19.1 & 29.6 \\
Oat hay & 11.1 & 24.3 \\
Clover hay & 2.7 & 11.1 \\
Dried distillers grains & 7.5 & 4.0 \\
Soybean + molasses & 2.2 & - \\
By-product of lactose industry & 3.9 & 3.3 \\
Calcium salts of FA & 1.2 & 1.6 \\
Salt & 0.8 & 0.5 \\
Urea & 0.4 & 0.3 \\
Calcium bicarbonate & 0.9 & - \\
Limestone & 0.7 & - \\
Vitamins and minerals ${ }^{1}$ & 0.1 & 0.1 \\
Chemical composition & & \\
NE ${ }^{2}$ (Mcal/kg) & 1.77 & 1.68 \\
CP & 16.6 & 16.0 \\
NDF & 32.6 & 38 \\
Forage NDF & 19.4 & 33.1 \\
Ether extract & 4.14 & 3.04 \\
P & 0.90 & 0.94 \\
Co & 0.44 & 0.40 \\
\hline
\end{tabular}

${ }^{1}$ Contained (per kilogram): 20,000,000 IU of vitamin A, 2,000,000 IU of vitamin D, 15,000 IU of vitamin E, $6,000 \mathrm{mg}$ of $\mathrm{Mn}, 6,000 \mathrm{mg}$ of $\mathrm{Zn}, 2,000 \mathrm{mg}$ of Fe, 1,500 $\mathrm{mg}$ of $\mathrm{Cu}, 120 \mathrm{mg}$ of I, $50 \mathrm{mg}$ of Se, and 20 $\mathrm{mg}$ of Co.

${ }^{2}$ Calculated using NRC (2001) values.

\section{Lipid Extraction from Plasma and Milk}

Chemicals and Reagents. Methanol and chloroform (both analytical reagent grade; Bio-Lab Ltd., Jerusalem, Israel) were used to extract the lipids. Chloroform and ethanol (used at 97:3 vol/vol, both analytical reagent grade) and methanol (HPLC grade; Bio-Lab Ltd.) were used for HPLC analysis. Triolein (>99\% pure; Supelco Inc., Bellefonte, PA) was used as the TG standard. The PL standards were supplied by SigmaAldrich Ltd. Israel (Rehovot, Israel) and consisted of 1,2-dioleoyl-sn-glycero-3-phosphoethanolamine (PE; $10 \mathrm{mg}$ of $\mathrm{PL} / \mathrm{mL}$ of $\mathrm{CHCl}_{3}$, purity $99 \%$ ), L- $\alpha$ phosphatidylinositol ammonium salt (PI; from bovine liver, purity $98 \%)$, 1,2-dioleoyl-sn-glycerol-3-phospho-L-serine sodium salt (PS; purity 95\%), 1,2-dioleoyl-sn-glycero3-phosphocholine (PC; purity $\geq 99 \%$ ), and sphingomyelin (SM; from bovine brain, purity 97\%); CLA (cis-9,trans-11 linoleic acid, purity >95\%) was used as a standard for FFA. For the gas chromatography analy- sis, analytical reagent-grade methanol (Bio-Lab Ltd.), petroleum ether (Gadot Laboratory Supplies Ltd., Netanya, Israel), and sulfuric acid (Bet Dekel, Ra'anana, Israel) were used. Retention times were determined by injection of commercial standard mixes of PL and TG.

Extraction of Total Lipids from Milk and Plasma. Total lipids were extracted from the milk using a protocol adapted from the cold-extraction procedure developed by Folch et al. (1957), as previously described (Mesilati-Stahy et al., 2012). Briefly, each sample was extracted twice, once for lipid analysis by normal-phase LC and once for FA analysis by GC. Total lipids were extracted from $0.5 \mathrm{~mL}$ of milk with methanol-chloroform-water (1:2:0.6, vol/vol/vol). After the solvent was evaporated under vacuum, $100 \mu \mathrm{L}$ of chloroform-ethanol $(3 \%, \mathrm{vol} / \mathrm{vol})$ was added. Total extracted lipids were stored at $-20^{\circ} \mathrm{C}$ until further analysis. For gas chromatography analysis, FAME were generated by methyl esterification with $5 \%$ (vol/vol) methanolic $\mathrm{H}_{2} \mathrm{SO}_{4}$ in $65^{\circ} \mathrm{C}$ for $1 \mathrm{~h}$. After adding 1.9 $\mathrm{mL}$ of petroleum ether and $3.5 \mathrm{~mL}$ of double-distilled water, the upper layer was collected, evaporated under nitrogen flow, and dissolved in a final volume of $100 \mu \mathrm{L}$ of petroleum ether before injection into the gas chromatograph.

\section{GC Analysis of FA}

Chromatographic analysis was performed with a gas chromatograph (Agilent Technologies Inc., Santa Clara, CA) equipped with a fused-silica capillary column (60 $\mathrm{m} \times 0.25$ mm i.d., DB-23; Agilent Technologies Inc.), as previously described (Mesilati-Stahy et al., 2012). Briefly, the oven temperature was programmed from 130 to $170^{\circ} \mathrm{C}$ at a rate of $27^{\circ} \mathrm{C} / \mathrm{min}$, from 170 to $215^{\circ} \mathrm{C}$ at a rate of $2^{\circ} \mathrm{C} / \mathrm{min}$ and held at $215^{\circ} \mathrm{C}$ for $8 \mathrm{~min}$, and then from 215 to $250^{\circ} \mathrm{C}$ at a rate of $40^{\circ} \mathrm{C} / \mathrm{min}$ and held at $250^{\circ} \mathrm{C}$ for $5 \mathrm{~min}$. The run time was $37.9 \mathrm{~min}$. Fatty acid composition was calculated as mole percentage of total FA moles within each sample.

\section{Analysis of Polar and Neutral Lipids from Milk}

Polar and neutral lipids were identified and quantified by HPLC (HP 1200; Agilent Technologies Inc.) combined with an evaporative light-scattering detector (Agilent Technologies Inc.) according to a previously described protocol for normal-phase lipid separation (Mesilati-Stahy et al., 2012). Briefly, the temperature was set at $65^{\circ} \mathrm{C}$, with nitrogen pressure of $390 \pm 10$ $\mathrm{kPa}$ and sensitivity (gain) of 5 for the first 12 min and then 9 until the end of the run. The separation process was managed by ChemStation software (Agilent Technologies Inc.) for data acquisition from the evaporative 
light-scattering detector. Lipids were identified by the use of external standards: triacylglycerol, diacylglycerol, monoacylglycerol, FFA, cholesterol, PE, PS, PI, PC, and SM. Polar and neutral lipids were quantified according to their weight percentage as previously described (Mesilati-Stahy et al., 2012). Cholesterol and PL calibration curves were calculated by applying the power-model equations to the area under the curve and concentration values: cholesterol: $\mathrm{y}=0.1016 \mathrm{x}^{0.49}$ $\left(\mathrm{R}^{2}=0.97\right) ;$ FFA: $\mathrm{y}=1.73 \mathrm{x}^{0.41}\left(\mathrm{R}^{2}=0.99\right)$; PS: $\mathrm{y}=$ $0.0824 \mathrm{x}^{0.7645}\left(\mathrm{R}^{2}=0.99\right)$; PE: $\mathrm{y}=0.035 \mathrm{x}^{0.63}\left(\mathrm{R}^{2}=0.99\right)$; PI: $y=0.114 x^{0.607}\left(R^{2}=0.99\right) ; P C: y=0.051 x^{0.603}\left(R^{2}\right.$ $=0.99)$; SM: $\mathrm{y}=0.11 \mathrm{x}^{0.62}\left(\mathrm{R}^{2}=0.99\right)$. The sum of the glycerol, PL, SM, and cholesterol concentrations was regarded as total membrane weight (100\%). The weight of each of the polar lipids in $1 \mathrm{~mL}$ of milk was calculated according to the standard curves, and its weight percentage of membrane lipids $(\mathrm{PE}+\mathrm{PI}+\mathrm{PC}$ $+\mathrm{SM}+$ cholesterol) was determined.

\section{MFG Size Analysis}

The MFG sizes were measured in raw, fresh milk samples in duplicate using a particle size analyzer with a single modular light-scattering system (Microtrac UPA, North Wales, UK). For each milk sample, the fat globule size was calculated as the mean diameter (in microns) of the area distribution of the particles in solution obtained from two 180-s scans; mean diameter $=\Sigma \mathrm{V}_{\mathrm{i}} / \Sigma\left(\mathrm{V}_{\mathrm{i}} / \mathrm{d}_{\mathrm{i}}\right)$, where $\mathrm{V}=$ volume percentage in channel size, $d=$ channel diameter (width of light path), and $i$ is the effect of the ith measurement. To prevent artifactual submicron-sized globules, each milk fraction consisting of the smallest MFG was measured once with the addition of EDTA for casein micelle dissociation.

\section{Study Design}

The first 2 wk of each period were defined as an adaptation period between treatments and only samples obtained from wk 3 and 4 of each cycle were used for statistical analysis. The BW changes were calculated as the difference between the individual BW at the beginning of the first week and that at the end of the last week of each period. Weekly milk yield for each cow was calculated as a mean of the recorded daily milk yield on the sampling day and on the previous and successive day.

\section{Statistical Analysis}

Data were subjected to the mixed ANOVA model REML method of JMP Pro software (version 9; SAS
Institute Inc., Cary, NC). Continuous variables (milk yield and composition; milk solids, FA, and polar lipid concentrations and compositions; MFG size; and insulin and NEFA concentrations) were analyzed as repeated measurements. Treatment, period, and group were analyzed as fixed effects, whereas the cow was analyzed as random effect in the model. Week was included as a continuous variable and week $\times$ treatment effect was included in the model. Differences in BW were calculated as differences between wk 4 and 1 of each treatment cycle and the model included period, group, and treatment as fixed effects and cow as random effect. Significance was set at 0.05 and tendencies were reported at $0.05<P \leq 0.1$.

\section{RESULTS}

\section{Dietary FA Composition}

The FA compositions of the LCHF and HCLF diets are presented in Table 2. The overall FA profile was similar between the 2 diets, with 2 main differences: linoleic acid (C18:2n-6) concentration tended to be higher (5\%) in the HCLF diet, whereas linolenic acid was $1 \%$ higher in the LCHF diet. Overall PUFA concentration tended to be higher $(4 \%)$ in the HCLF diet.

\section{BW, DMI, and Hormone and Metabolite Concentrations in Plasma}

Body weight and plasma metabolite and hormone concentrations are presented in Table 3 . The effects of treatment on $\mathrm{BW}$ gain (or loss) tended to be different $(P=0.07)$; cows lost $6.6 \mathrm{~kg}$ during the LCHF treatment and gained $4 \mathrm{~kg}$ during the HCLF period. Higher plasma insulin and glucose concentrations $(P<0.001$ and 0.03 , respectively), were found in the HCLF versus LCHF diet. Plasma NEFA concentrations were almost 2 -fold higher in the LCHF versus HCLF diets $(P<$ $0.001)$.

\section{Plasma FA Concentrations}

Plasma FA concentrations are presented in Table 4. The concentrations of several FA, mainly those derived from the diet and endogenous metabolism, were altered. Differences were observed between treatments in the concentration of palmitoleic (C16:1n-7), oleic (cis C18:1n-9), and linolenic (C18:3n-3) acids, which were 33,17 , and $32 \%(P=0.002,0.05$, and 0.003$)$ higher, respectively, in the LCHF versus the HCLF diet. Also, a tendency toward higher $(17 \%)$ concentration of eicosapentaenoic acid (C20:5n-3) was found in the LCHF versus the HCLF diet $(P=0.08)$. 
Table 2. Least squares means of the TMR FA composition (mol \%) in the high-concentrate, low-forage (HCLF) and low-concentrate, high-forage (LCHF) diets

\begin{tabular}{|c|c|c|c|c|}
\hline \multirow[b]{2}{*}{$\mathrm{FA}^{1}$} & \multicolumn{2}{|c|}{ Treatment } & \multirow[b]{2}{*}{ SEM } & \multirow[b]{2}{*}{$P$-value } \\
\hline & HCLF & LCHF & & \\
\hline C6:0 & 0.44 & 0.50 & 0.04 & 0.43 \\
\hline $\mathrm{C} 8: 0$ & 0.97 & 0.96 & 0.15 & 0.97 \\
\hline C10:0 & 0.09 & 0.09 & 0.02 & 0.62 \\
\hline C11:0 & 0.016 & 0.01 & 0.003 & 0.39 \\
\hline C12:0 & 0.56 & 0.79 & 0.008 & 0.003 \\
\hline C13:0 & 0.017 & 0.022 & 0.0008 & 0.07 \\
\hline C14:0 & 1.06 & 1.23 & 0.13 & 0.48 \\
\hline C14:1 & 0.01 & 0.01 & 0.003 & 0.86 \\
\hline C15:0 & 0.09 & 0.12 & 0.007 & 0.10 \\
\hline C15:1 & $\mathrm{ND}^{2}$ & 0.009 & 0.006 & 0.42 \\
\hline C16:0 & 32.63 & 35.73 & 0.79 & 0.11 \\
\hline C16:1n-7 & 0.29 & 0.36 & 0.008 & 0.02 \\
\hline C17:0 & 0.16 & 0.19 & 0.006 & 0.08 \\
\hline C18:0 & 4.06 & 4.46 & 0.08 & 0.08 \\
\hline trans $\mathrm{C} 18: 1 \mathrm{n}-9$ & 0.11 & 0.13 & 0.002 & 0.04 \\
\hline cis $\mathrm{C} 18: 1 \mathrm{n}-9$ & 26.03 & 25.43 & 0.44 & 0.44 \\
\hline C18:1n-7 & 0.88 & 0.81 & 0.023 & 0.16 \\
\hline cis $\mathrm{C} 18: 2 \mathrm{n}-6$ & 28.31 & 23.71 & 0.97 & 0.08 \\
\hline C18:3n-6 & 0.06 & 0.01 & 0.047 & 0.53 \\
\hline C18:3n-3 & 2.03 & 2.82 & 0.08 & 0.02 \\
\hline C20:0 & 0.46 & 0.51 & 0.01 & 0.09 \\
\hline $\mathrm{C} 20: 1 \mathrm{n}-9$ & 0.19 & 0.17 & 0.006 & 0.15 \\
\hline C20:2n-6 & 0.01 & 0.01 & 0.01 & 0.99 \\
\hline C20:5n-3 & 0.07 & 0.08 & 0.01 & 0.69 \\
\hline C20:3n-6 & ND & 0.05 & 0.002 & 0.01 \\
\hline C22:0 & 0.3 & 0.34 & 0.02 & 0.09 \\
\hline $\mathrm{C} 22: 1$ & 0.75 & 0.92 & 0.17 & 0.57 \\
\hline C23:0 & 0.07 & 0.1 & 0.006 & 0.09 \\
\hline C24:0 & 0.28 & 0.32 & 0.13 & 0.13 \\
\hline$\Sigma$ SFA & 41.22 & 45.44 & 1.25 & 0.14 \\
\hline$\Sigma$ MUFA & 28.27 & 27.85 & 0.4 & 0.54 \\
\hline$\Sigma$ PUFA & 30.49 & 26.70 & 0.85 & 0.09 \\
\hline इn-6 PUFA & 28.39 & 23.74 & 0.93 & 0.07 \\
\hline इn-3 PUFA & 2.10 & 2.91 & 0.09 & 0.03 \\
\hline
\end{tabular}

${ }^{1}$ Fatty acid composition was calculated as the molar percentage of a specific FA from the sum of moles of all recognized FA in the sample.

${ }^{2} \mathrm{ND}=$ not detectable

\section{Milk Yield and Composition and MFG Size}

Daily milk yield and the yields of fat, protein, and lactose were $26,14,35$, and $27 \%$ higher $(P<0.001)$, respectively, in the HCLF diet than in the LCHF diet (Table 5). Milk yield was the only factor affected by time by treatment interaction $(P=0.004)$. Between wk 3 and 4 of each period, the milk yield increased by $1.3 \mathrm{~kg} / \mathrm{d}$ in the HCLF diet and decreased by $1.25 \mathrm{~kg} / \mathrm{d}$ in the LCHF diet. The concentrations of milk protein and lactose were elevated, whereas the concentration of fat was lower in the HCLF treatment group. The mean diameter of MFG tended to be smaller in the HCLF group than in the LCHF group $(P=0.1$; Table 5$)$.

\section{Milk FA Composition}

Concentrations of most of the FA in the milk differed between the HCLF and LCHF diets (Table 6). Most notably, myristic acid (C14:0) was $2 \%$ higher $(P<$ 0.001 ), whereas oleic acid (cis C18:1n-9) was $3 \%$ lower $(P<0.001)$ in the HCLF versus LCHF diet. Similar to the ration composition, linoleic acid (cis C18:2n-6) was $30 \%$ higher in the HCLF versus LCHF diet, which could also explain the elevated trans linoleic acid (trans C18:2) concentrations $(P=0.001)$. Both linoleic and trans linoleic acids were affected by time by treatment interaction $(P<0.001)$. The dietary treatments altered the proportion of all FA subgroups in milk fat (Table 6). Milk produced under the HCLF diet had $20 \%$ higher concentrations of FA with less than 16 carbons $(P<$ 0.001), which are considered to be the product of de novo synthesis within the mammary cells (Palmquist et al., 1969), and $2 \%$ higher SFA $(P=0.016)$ and $24 \%$ higher PUFA concentration compared with the LCHF treatment $(P<0.001)$. In addition, the HCLF diet resulted in $27 \%$ higher n- 6 FA concentration $(P<0.001)$ than the LCHF diet. The concentrations of both PUFA 
Table 3. Dry matter intake and plasma metabolite and hormone concentrations in cows fed high-concentrate, low-forage (HCLF) or low-concentrate, high-forage (LCHF) diets

\begin{tabular}{|c|c|c|c|c|}
\hline \multirow[b]{2}{*}{ Item } & \multicolumn{2}{|c|}{ Treatment } & \multirow[b]{2}{*}{ SEM } & \multirow[b]{2}{*}{$P$-value } \\
\hline & HCLF & LCHF & & \\
\hline$\overline{\Delta \mathrm{BW}^{1}(\mathrm{~kg})}$ & 4.0 & -6.7 & 4.1 & 0.07 \\
\hline Insulin $(\mu \mathrm{IU} / \mathrm{mL})$ & 9.9 & 5.3 & 0.8 & $<0.001$ \\
\hline Glucose $(\mathrm{mg} / \mathrm{dL})$ & 68.2 & 61.9 & 2.6 & 0.03 \\
\hline NEFA $(\mu \mathrm{Eq} / \mathrm{L})$ & 150.7 & 279.2 & 19.9 & $<0.001$ \\
\hline
\end{tabular}

${ }^{1}$ Difference between BW in wk 4 and 1 of each experimental period.

and n- 6 FA were affected by treatment by time interaction $(P=0.05$ and 0.01 , respectively).

\section{MFGM Daily Yield and Composition}

The PL and cholesterol daily yields are presented in Table 7. The sum of all PL daily yields increased (34\%) in the HCLF diet compared with the LCHF diet $(P$ $=0.003)$. Daily SM, PI, PC, and PE yields were 28,
22,58 , and $22 \%$ higher, respectively $(P=0.03,0.002$, 0.00 , and 0.004 , respectively), with the HCLF versus LCHF diet (Table 7). The daily yield of PS tended to be higher $(34 \%)$ in the HCLF versus the LCHF diet $(P$ $=0.08$ ). The daily yield of cholesterol was $65 \%$ higher in the HCLF diet $(P=0.002)$.

Because the mean MFG diameter was altered by diet, the polar lipid composition was determined (Figure 1). Smaller MFG in the HCLF treatment had 14 and $7 \%$

Table 4. Least squares means of FA in the plasma $(\mathrm{mg} / \mathrm{mL})$ of cows fed high-concentrate, low-forage (HCLF) and low-concentrate, high-forage (LCHF) diets

\begin{tabular}{|c|c|c|c|c|}
\hline \multirow[b]{2}{*}{ FA } & \multicolumn{2}{|c|}{ Treatment } & \multirow[b]{2}{*}{ SEM } & \multirow[b]{2}{*}{$P$-value } \\
\hline & HCLF & LCHF & & \\
\hline $\mathrm{C} 6: 0$ & 0.93 & 0.85 & 0.21 & 0.75 \\
\hline $\mathrm{C} 8: 0$ & 4.66 & 4.13 & 0.3 & 0.13 \\
\hline C10:0 & 0.31 & 0.53 & 0.17 & 0.31 \\
\hline C11:0 & 0.08 & 0.09 & 0.02 & 0.87 \\
\hline $\mathrm{C} 12: 0$ & 0.36 & 0.35 & 0.03 & 0.94 \\
\hline C13:0 & 0.14 & 0.14 & 0.01 & 0.88 \\
\hline C14:0 & 1.99 & 2.22 & 0.35 & 0.60 \\
\hline C14:1 & 0.63 & 0.63 & 0.07 & 0.98 \\
\hline C15:0 & 0.87 & 0.89 & 0.06 & 0.85 \\
\hline C15:1 & 1.51 & 1.43 & 0.12 & 0.58 \\
\hline C16:0 & 31.5 & 31.6 & 2.7 & 0.97 \\
\hline C16:1n-7 & 0.9 & 1.2 & 0.08 & 0.002 \\
\hline C17:0 & 1.95 & 1.96 & 0.15 & 0.94 \\
\hline C18:0 & 42.37 & 39.46 & 3.53 & 0.58 \\
\hline trans $\mathrm{C} 18: 1 \mathrm{n}-9$ & 0.83 & 0.69 & 0.09 & 0.15 \\
\hline cis C18:1n-9 & 15.65 & 18.44 & 1.24 & 0.05 \\
\hline C18:1n-7 & 0.91 & 0.92 & 0.08 & 0.91 \\
\hline trans $\mathrm{C} 18: 2 \mathrm{n}-6$ & 0.07 & 0.05 & 0.02 & 0.52 \\
\hline cis $\mathrm{C} 18: 2 \mathrm{n}-6$ & 99.84 & 90.96 & 7.97 & 0.35 \\
\hline C18:3n-6 & 2.06 & 1.96 & 0.18 & 0.64 \\
\hline $\mathrm{C} 18: 3 \mathrm{n}-3$ & 2.45 & 3.23 & 0.19 & 0.003 \\
\hline C20:0 & 0.22 & 0.20 & 0.02 & 0.51 \\
\hline C20:1n-9 & 0.07 & 0.07 & 0.01 & 0.94 \\
\hline $\mathrm{C} 20: 2 \mathrm{n}-6$ & 0.33 & 0.33 & 0.03 & 0.78 \\
\hline C20:3 & 7.06 & 6.35 & 0.61 & 0.33 \\
\hline C20:4n-6 & 5.86 & 6.70 & 0.46 & 0.13 \\
\hline C21:0 & 0.06 & 0.11 & 0.04 & 0.35 \\
\hline $\mathrm{C} 20: 5 n-3$ & 0.51 & 0.60 & 0.04 & 0.08 \\
\hline C22:0 & 0.30 & 0.27 & 0.02 & 0.22 \\
\hline C22:1 & 0.46 & 0.41 & 0.03 & 0.22 \\
\hline $\mathrm{C} 23: 0$ & 0.30 & 0.32 & 0.02 & 0.33 \\
\hline $\mathrm{C} 22: 4 \mathrm{n}-6$ & 1.43 & 1.28 & 0.1 & 0.25 \\
\hline $\mathrm{C} 24: 0$ & 0.60 & 0.56 & 0.06 & 0.54 \\
\hline C22:6n-3 & 0.21 & 0.25 & 0.04 & 0.43 \\
\hline $\mathrm{C} 24: 1$ & 0.06 & 0.05 & 0.01 & 0.34 \\
\hline
\end{tabular}


Table 5. Least squares means of milk yield and composition and mean milk fat globule (MFG) diameter in cows fed high-concentrate, low-forage (HCLF) and low-concentrate, high-forage (LCHF) diets

\begin{tabular}{|c|c|c|c|c|}
\hline \multirow[b]{2}{*}{ Item } & \multicolumn{2}{|c|}{ Treatment } & \multirow[b]{2}{*}{ SEM } & \multirow[b]{2}{*}{$P$-value } \\
\hline & HCLF & $\mathrm{LCHF}$ & & \\
\hline Milk yield $^{1}(\mathrm{~kg} / \mathrm{d})$ & 40.8 & 32.3 & 1.3 & $<0.001$ \\
\hline Fat $(\mathrm{kg} / \mathrm{d})$ & 1.48 & 1.30 & 0.05 & 0.001 \\
\hline Protein $(\mathrm{kg} / \mathrm{d})$ & 1.35 & 1.00 & 0.04 & $<0.001$ \\
\hline Lactose $(\mathrm{kg} / \mathrm{d})$ & 2.03 & 1.6 & 0.07 & $<0.001$ \\
\hline Fat $(\%)$ & 3.65 & 4.05 & 0.1 & $<0.001$ \\
\hline Protein (\%) & 3.29 & 3.11 & 0.05 & $<0.001$ \\
\hline Lactose (\%) & 4.9 & 4.8 & 0.04 & $<0.001$ \\
\hline MFG diameter ${ }^{2}(\mu \mathrm{m})$ & 3.3 & 3.51 & 0.1 & 0.1 \\
\hline
\end{tabular}

${ }^{1}$ Treatment $\times$ week interaction was found only significant for milk yield $(P=0.04)$.

${ }^{2}$ Mean of volume weighted diameter.

higher cholesterol and $\mathrm{PC}(P=0.04)$, respectively, and $19 \%$ lower PS $(P=0.04)$ concentrations compared with the larger globules secreted into milk under the LCHF treatment.

\section{DISCUSSION}

We studied the association between diet-induced changes in the yield and composition of milk constituents and MFG size and composition. The cows' response to the LCHF diet included decreased BW, increased plasma NEFA concentration, decreased milk yield, and increased milk fat concentration, compared with the HCLF diet. Consequently, MFG size tended to increase and the lipid fraction of its membrane was remodeled. The association between mean MFG diameter and total fat concentration in the milk was similar to that reported when dairy cow rations were supplemented with fish meal (Avramis et al., 2003), or with concentrates with different FA composition (Wiking et al., 2003). Further research, conducted over a longer period of time, is required to determine how constant the dietary effect is on fat content and yield, and consequently, MFG structure.

During the LCHF-feeding period, milk, protein, lactose, and fat yields decreased. Also, during the HCLF diet, insulin and glucose levels were higher, most probably attributed to the increased propionate production in the rumen upon ingestion of a high-grain diet (Bergman, 1990).

Increased propionate production by the rumen bacteria upon ingestion of a high-grain diet will induce gluconeogenesis in the liver and increase glucose production and plasma insulin concentrations (Harmon, 1992; Ramanzin et al., 1997), as also found in the present study. Plasma glucose is the major precursor for lactose synthesis by the mammary gland cells (Hardwick et al., 1963) and, hence, may have contributed to the higher milk production with the HCLF diet. The fact that un- der the HCLF diet milk fat concentration was reduced while its yield was increased could be explained by the higher total amount of acetate produced in the rumen, whereas its proportion from total rumen VFA is expected to decrease when a high-grain diet is consumed (Bergman, 1990). Also, higher insulin concentration under the HCLF diet inhibits adipose lipolysis (Shennan and Peaker, 2000), which will result in lower NEFA concentrations and, hence, lower concentrations of long-chain FA in milk (>16 carbons; Corl et al., 2006), as was found with the HCLF diet herein. Nonetheless, under high-grain diets, acetate is not expected to be deficient for milk fat synthesis (Bauman and Griinari, 2001) and indeed fat yield under the HCLF diet was higher compared with the LCHF diet. The higher NEFA concentration under the LCHF diet was also reflected by higher plasma concentrations of oleic acid, which is one of the major FA constituents of adipose tissue. Higher oleic acid availability as preformed FA could also explain the higher MUFA concentration in milk during the LCHF treatment.

The higher milk, protein, and fat yields with the HCLF diet suggest greater productivity of the mammary gland, which has been found to be associated with the secretion of smaller MFG (Couvreur et al., 2007). Those authors suggested that the secretion of smaller globules is associated with higher production of milk constituents, including MFGM. This is in agreement with our findings of higher milk and protein yields, smaller MFG, and a higher (by 34\%) PL yield with the HCLF diet. As cholesterol is one of the MFGM constituents, a higher yield of cholesterol is expected during the HCLF diet.

Higher productivity of fat and protein in the mammary gland requires greater energy and reducing agents, which are provided by greater mitochondrial activity or more mitochondria (Davis and Bauman, 1974; Rudolph et al., 2007). Aside from providing energy to the cell, the mitochondria play a major role in membrane re- 
Table 6. Least squares means of FA composition of milk (mol \%) in cows fed high-concentrate, low-forage (HCLF) and low-concentrate, high-forage (LCHF) diets

\begin{tabular}{|c|c|c|c|c|}
\hline \multirow[b]{2}{*}{ FA } & \multicolumn{2}{|c|}{ Treatment } & \multirow[b]{2}{*}{ SEM } & \multirow[b]{2}{*}{$P$-value } \\
\hline & HCLF & $\mathrm{LCHF}$ & & \\
\hline $\mathrm{C} 6: 0$ & 0.23 & 0.22 & 0.03 & 0.78 \\
\hline C8:0 & 1.27 & 1.16 & 0.06 & 0.03 \\
\hline $\mathrm{C} 10: 0$ & 4.33 & 3.18 & 0.20 & $<0.001$ \\
\hline $\mathrm{C} 12: 0$ & 5.55 & 3.92 & 0.23 & $<0.001$ \\
\hline C13:0 & 0.17 & 0.10 & 0.009 & $<0.001$ \\
\hline C14:0 & 14.35 & 12.80 & 0.26 & $<0.001$ \\
\hline C14:1 & 1.01 & 0.89 & 0.06 & 0.04 \\
\hline $\mathrm{C} 15: 0$ & 1.07 & 0.95 & 0.04 & 0.006 \\
\hline C15:1 & 0.25 & 0.34 & 0.01 & $<0.001$ \\
\hline C16:0 & 33.42 & 35.51 & 0.35 & $<0.001$ \\
\hline C16:1n-7 & 1.48 & 1.65 & 0.07 & 0.069 \\
\hline $\mathrm{C} 17: 0$ & 0.42 & 0.50 & 0.01 & $<0.001$ \\
\hline $\mathrm{C} 17: 1$ & 0.17 & 0.18 & 0.004 & 0.22 \\
\hline C18:0 & 9.92 & 10.73 & 0.31 & 0.03 \\
\hline trans $\mathrm{C} 18: 1 \mathrm{n}-9$ & 0.55 & 0.49 & 0.02 & 0.04 \\
\hline cis C18:1n-9 & 19.80 & 22.56 & 0.45 & $<0.001$ \\
\hline C18:1n-7 & 0.84 & 0.72 & 0.03 & $<0.001$ \\
\hline trans $\mathrm{C} 18: 2 \mathrm{n}-6$ & 0.51 & 0.42 & 0.02 & $<0.001$ \\
\hline cis $\mathrm{C} 18: 2 \mathrm{n}-6$ & 3.79 & 2.94 & 0.09 & $<0.001$ \\
\hline C18:3n-6 & 0.08 & 0.09 & 0.009 & 0.23 \\
\hline C18:3n-3 & 0.18 & 0.20 & 0.005 & 0.001 \\
\hline C20:0 & 0.11 & 0.10 & 0.006 & 0.36 \\
\hline C20:1n-9 & 0.02 & 0.02 & 0.006 & 0.90 \\
\hline C20:3n-3 & 0.13 & 0.11 & 0.006 & 0.008 \\
\hline C20:4n-6 & 0.19 & 0.15 & 0.007 & $<0.001$ \\
\hline SFA & 70.90 & 69.2 & 0.64 & 0.016 \\
\hline MUFA & 24.17 & 26.87 & 0.62 & $<0.001$ \\
\hline PUFA & 4.91 & 3.95 & 0.1 & $<0.001$ \\
\hline$<\mathrm{C} 16: 0$ & 28.29 & 23.57 & 0.7 & $<0.001$ \\
\hline$>\mathrm{C} 16: 0$ & 38.26 & 40.94 & 0.68 & 0.001 \\
\hline $\mathrm{n}-6$ & 4.59 & 3.62 & 0.1 & $<0.001$ \\
\hline n-3 & 0.32 & 0.32 & 0.008 & 0.97 \\
\hline
\end{tabular}

modeling, especially via decarboxylation of PS to PE (Pereira et al., 2012). Therefore, greater mitochondrial activity under the HCLF diet needed to support the secretion of greater amounts of milk, protein, and fat could explain lower PS concentrations in the MFGM. It should be noted that the different PL can be syn- thesized from each other or de novo (Pereira et al., 2012) and, therefore, it is hard to establish a simple linear relationship between their concentrations. This could, in part, explain how although PS concentration was decreased during the HCLF diet, no concomitant increase in PE concentration was observed. Further-

Table 7. Yield ( $\mu \mathrm{g} / \mathrm{d}$; mean and SEM) of polar lipids in milk during the feeding period with high-concentrate, low-forage (HCLF) and low-concentrate, high-forage (LCHF) diets

\begin{tabular}{|c|c|c|c|c|}
\hline \multirow[b]{2}{*}{ Item $^{1}$} & \multicolumn{2}{|c|}{ Treatment } & \multirow[b]{2}{*}{ SEM } & \multirow[b]{2}{*}{$P$-value } \\
\hline & HCLF & LCHF & & \\
\hline Cholesterol & 4,432 & $2,681.3$ & 410.5 & 0.002 \\
\hline PI & 4,926 & $4,031.9$ & 209.3 & 0.002 \\
\hline $\mathrm{PE}$ & $5,981.2$ & $4,899.9$ & 419.4 & 0.04 \\
\hline PS & $2,703.3$ & $2,011.9$ & 332.1 & 0.08 \\
\hline $\mathrm{PC}$ & $7,807.6$ & $4,950.4$ & 765.6 & 0.004 \\
\hline SM & $7,347.9$ & $5,754.1$ & 617.3 & 0.034 \\
\hline Total membrane ${ }^{2}$ & $33,222.8$ & $24,184.3$ & $2,333.1$ & 0.002 \\
\hline Total $\mathrm{PL}^{3}$ & $28,790.8$ & $21,505.4$ & $1,969.7$ & 0.003 \\
\hline
\end{tabular}

${ }^{1} \mathrm{PI}=$ phosphatidylinositol; $\mathrm{PE}=$ phosphatidylethanolamine; $\mathrm{PS}=$ phosphatidylserine; $\mathrm{PC}=$ phosphatidylcholine; $\mathrm{SM}=$ sphingomyelin.

${ }^{2}$ Sum of concentrations or yields of all polar lipids, including phospholipids and cholesterol.

${ }^{3}$ Sum of concentrations or yields of phospholipids. 


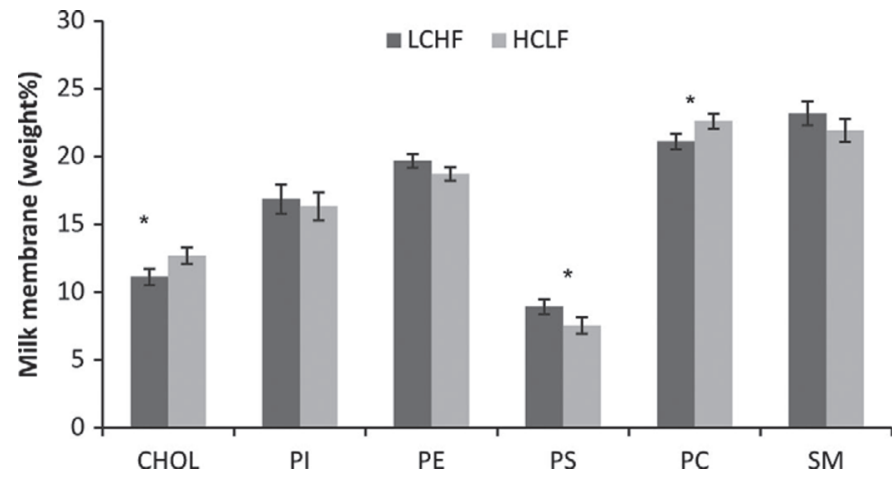

Figure 1. Weight percentage of phospholipids during feeding with high-concentrate, low-forage (HCLF) and low-concentrate, high-forage $(\mathrm{LCHF})$ diets. $\mathrm{CHOL}=$ cholesterol; $\mathrm{PI}=$ phosphatidylinositol; $\mathrm{PE}=$ phosphatidylethanolamine; $\mathrm{PS}=$ phosphatidylserine; $\mathrm{PC}=$ phosphatidylcholine; $\mathrm{SM}=$ sphingomyelin. Values are mean $\pm \mathrm{SE} .{ }^{*} P<0.05$.

more, PE concentration could be further metabolized to PC by phosphatidylethanolamine methyl transferase (Pereira et al., 2012), which may have accounted for the elevated PC concentration under the HCLF treatment.

The modifications in milk polar lipid composition documented herein imply differences in the composition of the mammary epithelial cell membrane, which is the origin of the MFGM (Mather and Keenan, 1998). Cell-membrane remodeling might explain the different mean MFG diameters between treatments. In the mammary epithelium, before lipid droplets reach the apical pole of the cell, they can fuse with each other and grow substantially in size (Mather and Keenan, 1998). Coalescence and ripening of intracellular lipid droplets in adipocytes and hepatocytes can be modulated by the composition of their PL envelope (reviewed by Thiam et al., 2013). Specifically, PS concentration reduces the interfacial surface tension of the lipid droplet, which can result in fewer, larger droplets (reviewed by Thiam et al., 2013). In agreement with this, we found the secretion of larger globules to be associated with higher PS concentrations in the LCHF versus HCLF diet.

\section{CONCLUSIONS}

The results of the present study suggest that the regulatory mechanism underlying MFG size is the coregulation of milk constituent production and membrane PL composition. More specifically, the concentrations of stabilizing agents in the membrane were associated with altered MFG size and milk fat concentration and yield, suggesting that their specific synthesis or degradation pathways were associated with the lipogenic capacity of the mammary gland, which was altered by dietary treatment.

\section{REFERENCES}

Argov-Argaman, N., T. Mbogori, A. Shamay, K. Sabastian, and S. Mabjeesh. 2012. Hyperinsulinogenic clamp modulated milk fat globule lipid composition in goats. J. Dairy Sci. 95:5776-5787.

Argov-Argaman, N., K. Mida, B.-C. Cohen, M. Visker, and K. Hettinga. 2013. Milk fat content and DGAT1 genotype determine lipid composition of the milk fat globule membrane. PLoS ONE 8:e68707.

Avramis, C. A., H. Wang, B. W. McBride, T. C. Wright, and A. R. Hill. 2003. Physical and processing properties of milk, butter, and Cheddar cheese from cows fed supplemental fish meal. J. Dairy Sci. 86:2568-2576.

Bauman, D. E., and J. M. Griinari. 2001. Regulation and nutritional manipulation of milk fat: Low-fat milk syndrome. Livest. Prod. Sci. 70:15-29.

Bergman, E. N. 1990. Energy contributions of volatile fatty acids from the gastrointestinal tract in various species. Physiol. Rev. 70:567-590.

Bitman, J., and D. L. Wood. 1990. Changes in milk fat phospholipids during lactation. J. Dairy Sci. 73:1208-1216.

Burgess, J. W., T. A.-M. Neville, P. Rouillard, Z. Harder, D. S. Beanlands, and D. L. Sparks. 2005. Phosphatidylinositol increases HDL-C levels in humans. J. Lipid Res. 46:350-355.

Corl, B. A., S. T. Butler, W. R. Butler, and D. E. Bauman. 2006. Regulation of milk fat yield and fatty acid composition by insulin. J. Dairy Sci. 89:4172-4175.

Couvreur, S., C. Hurtaud, P. G. Marnet, P. Faverdin, and J. L. Peyraud. 2007. Composition of milk fat from cows selected for milk fat globule size and offered either fresh pasture or a corn silage-based diet. J. Dairy Sci. 90:392-403.

Davis, C. L., and D. E. Bauman. 1974. General metabolism associated with the synthesis of milk. Pages 3-30 in Lactation: A Comprehensive Treatise. Vol. 2. B. L. Larson and V. R. Smith, ed. Academic Press, New York, NY.

Dillehay, D. L., S. K. Webb, E.-M. Schmelz, and A. H. Merrill Jr. 1994. Dietary sphingomyelin inhibits 1,2-dimethylhydrazine-induced colon cancer in CF1 mice. J. Nutr. 124:615-620.

El-Zeini, H. M. 2006. Microstructure, rheological and geometrical properties of fat globules of milk from different animal species. Pol. J. Food Nutr. Sci. 15:147-154.

Folch, J., M. Lees, and G. H. Sloane Stanley. 1957. Simple method for the isolation and purification of total lipids from animal tissues. J. Biol. Chem. 226:497-509.

Hardwick, D. C., J. L. Linzell, and T. B. Mepham. 1963. The metabolism of acetate and glucose by the isolated perfused udder. 2 . The contribution of acetate and glucose to carbon dioxide and milk constituents. Biochem. J. 88:213-220.

Harmon, D. L. 1992. Impact of nutrition on pancreatic exocrine and endocrine secretion in ruminants. J. Anim. Sci. 70:1290-1301.

IDF (International Dairy Federation). 2000. Whole milk: Determination of milk fat, protein and lactose content-Guidance on the operation of mid-infrared instruments. IDF 141C:2000. IDF, Brussels, Belgium.

Jensen, R. G. 2002. The composition of bovine milk lipids: January 1995 to December 2000. J. Dairy Sci. 85:295-350.

King, J. O. L. 1957. The association between fat percentage in cows' milk and the size and number of the fat globules. J. Dairy Res. 24:198-200.

Lopez, C., V. Briard-Bion, O. Menard, F. Rousseau, P. Pradel, and J.-M. Besle. 2008. Phospholipid, sphingolipid, and fatty acid compositions of the milk fat globule membrane are modified by diet. J. Agric. Food Chem. 56:5226-5236.

Mather, I. H., and T. W. Keenan. 1998. Origin and secretion of milk lipids. J. Mammary Gland Biol. Neoplasia 3:259-273.

Ménard, O., S. Ahmad, F. Rousseau, V. Briard-Bion, F. Gaucheron, and C. Lopez. 2010. Buffalo vs. cow milk fat globules: Size distribution, zeta-potential, compositions in total fatty acids and in polar lipids from the milk fat globule membrane. Food Chem. 120:544-551. 
Mesilati-Stahy, R., and N. Argov-Argaman. 2014. The relationship between size and lipid composition of the bovine milk fat globule is modulated by lactation stage. Food Chem. 145:562-570.

Mesilati-Stahy, R., H. Malka, and N. Argov-Argaman. 2012. Association of plasma insulin concentration to fatty acid distribution between milk fat and membrane synthesis. J. Dairy Sci. 95:17671775 .

Michalski, M.-C., B. Camier, V. Briard, N. Leconte, J.-Y. Gassi, H. Goudédranche, F. Michel, and J. Fauquant. 2004. The size of native milk fat globules affects physico-chemical and functional properties of Emmental cheese. Lait 84:343-358.

Michalski, M. C., R. Cariou, F. Michel, and C. Garnier. 2002. Native vs. damaged milk fat globules: Membrane properties affect the viscoelasticity of milk gels. J. Dairy Sci. 85:2451-2461.

Michalski, M.-C., J.-Y. Gassi, M.-H. Famelart, N. Leconte, B. Camier, F. Michel, and V. Briard. 2003. The size of native milk fat globules affects physico-chemical and sensory properties of Camembert cheese. Lait 83:131-143.

Mulder, H., and P. Walstra. 1974. The fat dispersion. Pages 54-66 in The Milk Fat Globule. Emulsion Science as Applied to Milk Products and Comparable Foods. H. Mulder and P. Walstra, ed. Center for Agricultural Publishing and Documentation, Wageningen, the Netherlands.

NRC. 2001. Nutrient Requirements of Dairy Cattle. 7th rev. ed. National Academy Press, Washington, DC.

Palmquist, D. L., C. L. Davis, R. E. Brown, and D. S. Sachan. 1969. Availability and metabolism of various substrates in ruminants. $\mathrm{V}$.
Entry rate into the body and incorporation into milk fat of $\mathrm{D}(-)$ 3-hydroxybutyrate. J. Dairy Sci. 52:633-638.

Pereira, L., J. P. Girardi, and M. Bakovic. 2012. Forms, crosstalks, and the role of phospholipid biosynthesis in autophagy. Int. J. Cell Biol. 2012:931956.http://dx.doi.org/ 10.1155/2012/931956.

Ramanzin, M., L. Bailoni, S. Schiavon, and G. Bittante. 1997. Effect of monensin on milk production and efficiency of dairy cows fed two diets differing in forage to concentrate ratios. J. Dairy Sci. 80:1136-1142.

Rudolph, M. C., J. L. McManaman, T. Phang, T. Russell, D. J. Kominsky, N. J. Serkova, T. Stein, S. M. Anderson, and M. C. Neville. 2007. Metabolic regulation in the lactating mammary gland: a lipid synthesizing machine. Physiol. Genomics 28:323-336.

Shennan, D. B., and M. Peaker. 2000. Transport of milk constituents by the mammary gland. Physiol. Rev. 80:925-951.

Thiam, A. R., R. V. Farese Jr., and C. T. Walther. 2013. The biophysics and cell biology of lipid droplets. Nat. Rev. Mol. Cell Biol. 14:775-786.

Walstra, P. 1969. Studies on milk fat dispersion. II. The globule-size distribution of cow's milk. Neth. Milk Dairy J. 23:99-110.

Wiking, L., L. Björck, and J. H. Nielsen. 2003. Influence of feed composition on stability of fat globules during pumping of raw milk. Int. Dairy J. 13:797-803.

Wiking, L., J. Stagsted, L. Björck, and J. H. Nielsen. 2004. Milk fat globule size is affected by fat production in dairy cows. Int. Dairy J. 14:909-913. 